\title{
The lability of behavior as a marker of comorbid depression and anxiety
}

\author{
Irina N. Trofimova, William Sulis
}

Collective Intelligence Laboratory, Department of Psychiatry and Behavioral Neuroscience, McMaster University, Hamilton, Canada. E-mail: itrofimova@sympatico.ca

Received 30 April 2010; revised 29 May 2010; accepted 7 June 2010.

\begin{abstract}
This study examines nine dynamical and three emotional aspects of behavior in depression and anxiety, singly and comorbidly. The study employs the Structure of Temperament Questionnaire Compact (STQ 77), whose 12 scales assess the energetic, lability and sensitivity aspects of behavior in the physical, social, mental and emotional domains. The STQ 77 was administered to 86 patients with Major Depression, 85 patients with an anxiety disorder, 43 patients with comorbid depression and anxiety, and 71 subjects without depression or anxiety disorder all presenting to a private outpatient clinical practice. Results: 1) Depression was associated with self-reports of increased impulsivity and rigidity of behavior; 2) Depressed patients reported significantly lower physical energy, tempo of physical activity and plasticity of behavior. The presence of comorbid anxiety further worsened these effects; 3) The ability to sustain attention on a mental task and to learn new information was lower in depressed patients than in other groups. Conclusions: comorbid depression and anxiety might be associates, decreasing adaptivity and the self-regulatory balance of behavior, leading to the development of extremes in behavioral reactivity (impulsivity and rigidity).
\end{abstract}

Keywords: Comorbid Depression and Anxiety; Behavioural Reactivity; Lability; STQ-77

\section{INTRODUCTION}

Psychiatry is focused on the biological factors associated with mental disorders, hence it has been natural to emphasize symptoms that have a psychobiological character such as psychomotor retardation, fatigue, inattention and so on. These symptoms reflect the impact of mood upon the dynamics of behavior, in particular, its energetics. There are many additional dynamical aspects, however, but these have been relatively neglected in studies of depression and anxiety and in comorbidity in particular. Studies into psychobiological correlates in comorbidity have identified relationships between mood and factors such as neuroticism, harm avoidance, self directedness [1] but not with activity per se. This leaves a significant gap in our current understanding of the biological underpinnings of depression and anxiety and their comorbidity. Even basic questions related to whether depression and anxiety are separate or interrelated remain unsettled $[2,3]$. Since the regulation of activity is a basic psychobiological attribute, it is reasonable, therefore, to consider additional measures and modes of investigation that highlight correlations between mood and activity in an effort to achieve a greater understanding.

Correlations between mood and activity partly formed the basis of the earliest attempts to understand human character. About 2400 years ago Hippocrates and then Galen described four types of "temperamentums", or mixtures of bodily chemical components. According to their theory, in a healthy individual this mixture is balanced, and an imbalance in this mixture causes noticeable and consistent patterns of behavior: choleric (impulsive), melancholic (depressive), phlegmatic (socially detached) and sanguine (manic). It is probably safe to say that the Hippocrates-Galen theory of temperaments was the earliest theory of mood and personality disorders linked to human physiology, even while it described only four conditions. The first attempt to describe the basic factors underlying these behavioral patterns was made by Immanuel Kant [4]. Kant suggested that the Hippocrates-Galen four "temperamentums" could be derived from two components, 1) "activity", or energetic strength in behavior, and 2) "feelings" (emotionality), or the ability to control emotional reactions while focusing on an action. Cholerics were described as emotional and energetic, Phlegmatics -as non-emotional and weak, Sanguines - as wellregulated and energetic, and Melancholics as emotional and weak.

These two factors, an "energetic" aspect and an 
"emotionality" aspect were echoed in the writings of many psychiatrists and psychologists during the 20th century. In spite of a diversity of labels given to these traits, universally they were presented as traits of temperament. Eysenck designed his version of the pair "Activity and Emotionality" as "Extraversion and Neuroticism", and the Eysenck Personality Questionnaire was used in several clinical investigations [5]. Thayer [6] proposed a similar model with dimensions of energetic arousal (energy vs. tiredness) and "tense arousal" (tension vs. calmness). Jeffrey Gray [7], separated two types of regulatory systems, calling them the Behavioural Activation System (BAS) and the Behavioural Inhibition System (BIS). An imbalance between these systems caused, according to Gray, clinically symptomatic behavior such as impulsivity (with an excess of BAS activation over BIS), anxiety-neuroticism (with an excess of BIS) and intermediate states of extraversion and withdrawal [8]. Other temperamental models tested in clinical practice include the Temperament and Character Inventory, TCI $[9,10]$, Pleasure-Arousability-Dominance, PAD [11], Dimensions of Temperament Survey-Revised [12], Happiness-Unhappiness model [13], Big Five model [14], and Temperament \& Personality Questionnaire [15].

Overall the list of temperament traits described in about 30 various temperament models and tests reported in the literature now exceeds 80 entries, and is not the subject of the present paper. The majority of these models have paid little attention to the multiple aspects of activity components, especially to the dynamical (energetic, tempo, plasticity) aspects, and the scales of multi-dimensional models have primarily considered aspects of emotionality, such as approach and withdrawal behavior. In contrast to these models, an experimental tradition involving the detailed study of aspects of activity, i.e. the dynamical properties of nervous systems (strength, mobility and balance) was started at the beginning of 20th century by Pavlov. During 30 years of experiments and extensive observations, Pavlov noticed that these properties might be linked to psychiatric disorders [16]. About the same time, observations from psychiatrists provided terminology which described consistent deficiencies in energetic and tempo-related features of behavior as contributing factors in psychiatric disorders. For example, concepts of "cyclothymia", "psychaesthesia" and "psychic tempo" suggested by the German psychiatrist Ernst Kretschmer [17].

Pavlov's tradition was continued in the experiments of Teplov, Nebylitsyn, Strelau and Rusalov throughout the 20th century. In the 1980's Rusalov studied consistent individual differences in psychophysiological and psychological data in a wide variety of settings, including: EEGs, evoked potentials, absolute thresholds in visual, auditory, and tactile modalities, strength of excitation and mobility in auditory and visual modalities, problem-solving in deterministic and probabilistic conditions, the speed of problem-solving using a variety of intellectual tests, the time spent in attempting unsolvable problems and the number of times a subject gave up while attempting to solve a task [18]. Based on these studies, Rusalov developed the Questionnaire of Formal-Dynamical Properties of Individuality later re-named as the Structure of Temperament Questionnaire (STQ). The STQ in its Extended version assesses 4 traits: 1) ergonicity (energetic component); 2) plasticity; 3) tempo of activity; and 4) emotionality, each according to three types of activity-physical ("objectrelated"), social-verbal and intellectual [19-22]. The Compact version of the STQ (STQ-77) was developed by a clinician for clinical usage as an abbreviated version of the Extended STQ, with additional scales following the neuropsychological models of Luria. The STQ-77 uses 6 out of 12 items from each original scale, rearranging and re-labeling the scales according to the traits of 1) arousal; 2) lability; and 3) sensitivity, each within the physical, social-verbal, and mental areas of activity, and emotionality, as shown in the Figure 1 [21,23]. A brief summary of the validation history of the Extended and Compact STQ is given in the Supplementary material.

In this paper, "temperament" refers to the consistent, biologically based dynamic aspects of behavior, and should not be conflated with "personality" which refers to those stable characteristics that arise through social developmental processes and social learning. Previous investigations of associations between temperament and depression and anxiety have mainly focused on issues of childhood temperament, and to a much lesser degree on adult temperament. The studies of the associations between adult temperament and depression showed that depression was associated with high so-called "harm avoidance" and low so-called "selfdirectedness" as measured by the TCI [9].

\begin{tabular}{|c|c|c|c|}
\hline & Energetic aspect & Lability & Sensitivity to \\
\hline $\begin{array}{l}\text { Mental } \\
\text { Activity }\end{array}$ & $\begin{array}{c}\text { Intellectual Ergonic- } \\
\text { ity, ERI }\end{array}$ & $\begin{array}{l}\text { Plasticity, } \\
\text { PL }\end{array}$ & $\begin{array}{c}\text {.. to probabilities, } \\
\text { PRO }\end{array}$ \\
\hline $\begin{array}{l}\text { Physical } \\
\text { Activity }\end{array}$ & $\begin{array}{c}\text { Motor Ergonicity, } \\
\text { ERM }\end{array}$ & $\begin{array}{c}\text { Motor Tempo, } \\
\text { TMMM }\end{array}$ & .. to sensations, SS \\
\hline $\begin{array}{c}\text { Social-verbal } \\
\text { Activity }\end{array}$ & $\begin{array}{c}\text { Social Ergonicity, } \\
\text { ERS }\end{array}$ & $\begin{array}{c}\text { Social Tempo, } \\
\text { TMSS }\end{array}$ & $\begin{array}{c}\text { to others/Empathy } \\
\text { EMP }\end{array}$ \\
\hline Emotionality & Self-confidence, $S \mathcal{L} F$ & $\begin{array}{c}\text { Impulsivity, } \\
\text { IMMP }\end{array}$ & $\mathcal{N}$ euroticism, $\mathcal{N} E \mathcal{U}$ \\
\hline
\end{tabular}

Figure 1. The STQ-77 structure and its temperament scales. 
The content of the harm-avoidance scale of the TCI includes the characteristics of anticipatory worry, fear of uncertainty, shyness and fatigability, and the content of the TCI self-directedness scale includes the characteristics of responsibility, purposefulness, resourcefulness, and self-acceptance. When analyzed against the STQ-77 scales, the TCI scale of Self-directedness includes features of the Plasticity scale of the STQ-77, and the fatigability descriptor in the TCI scale relates to the energetic components (Ergonicity) scales of the STQ-77.

Those few studies which investigated associations between adult temperament, depression or anxiety analyzed these disorders separately, without investigating the comorbidity condition. This is the first study to explore the impact of comorbidity between anxiety and depression and the resulting associations with patients' reports of symptoms related to the formal dynamical aspects of their activity (such as energetic, lability, sensitivity and emotionality aspects). Clinically, both depressive and anxiety disorders have significant impact on the organization and tempo of activity and the motivation and endurance of the patient. These manifest in symptoms such as psychomotor retardation, agitation, lack of motivation and interest, inattention, impaired learning under stress, and the like. It is an interesting question whether these symptoms are wholly state determined reflecting the transient effect of the illness on psychophysiological functioning, or whether there might exist underlying dynamical properties of the nervous system, which either predispose an individual to depression or anxiety or which predispose an individual to expressing depression or anxiety through these particular symptoms complexes. These symptoms form an essential part of the diagnostic criteria for these disorders.

The fundamental role that these symptoms play provides justification for examining how the dynamical aspects of activity may be related to the depressive and anxiety disorders that distort such expression. Thus the goal of the study was to investigate the relationships between the indicated disorders and patients' reports on their endurance, tempo, plasticity and emotionality of behavior.

\section{METHOD}

In this study we examined the intake records of 199 (86 males and 113 females) Caucasian Canadians, patients and associates of a private psychiatric and psychological practice located in Hamilton, Ontario, Canada and serving the Hamilton and Toronto areas. Eighty six subjects were diagnosed with Major Depressive Disorder on the basis of the structured DSM-IV clinical interview (conducted by licensed psychologist and psychiatrist), file review and the results of testing using the Beck Depression Inventory (scores of 20 or higher), Hamilton Depression Inventory (scores of 20 or higher on the Total scale) and Symptom CheckList-90 (scores of 40 or higher on the Depression scale). Eighty five subjects (31 males and 44 females) were diagnosed with a disorder within the DSM-IV Anxiety Disorders category (moderate to severe): GAD (78.6\%), PTSD or specific phobia $(16.7 \%)$, OCD (4.8\%) on the basis of the structured DSM-IV clinical interview, file review and the results of testing using the Beck Anxiety Inventory (scores of 16 or higher), State Trait Anxiety Inventory (scores of 61 or higher), Detailed Assessment of Post-traumatic Stress inventory, Post-Traumatic Stress diagnostic scale and Symptom CheckList-90 (scores of 31 or higher on the Anxiety scale). Within the patient group, 43 patients had comorbid depression and anxiety. The patient groups were compared against 71 control subjects in whom the diagnoses of depression or anxiety disorder were ruled out. Control subjects were also clients and patients of the same private practice. Demographic information about the sample is presented in Table 1.

During intake testing each patient completed the Compact Structure of Temperament Questionnaire (STQ-77) [21] and gave consent to use the data from their file for research purposes. The STQ-77 consists of 77 statements, assigned to 12 temperament scales (6 items each) and a validity scale (5 items, addressing social desirability bias), which are listed below. Subjects responded according to a 4-point Likert scale format: 1) "strongly disagree", 2) "disagree", 3) "agree", 4) "strongly agree". Protocols having scores of 15-20 on the validity scale were considered invalid as the respondents were likely to demonstrate a positive impression bias in their responses. The scales are:

1-3: Ergonicity group, scales of Motor, Social and Intellectual Ergonicity: the ability of an individual to sustain prolonged physical (ERM), social (ERS) or mental (ERI) activity.

4-5: Lability group, scales of Motor and Social Tempo: preferred speed of physical activity (TMM), speed of speech and reading and of other verbal activities (TMS) and Plasticity scale, assessing the ability to adapt quickly to changes in situations, to change the program of action, and to shift between different tasks (PL).

6-9: Sensitivity group: Sensitivity to Sensations scale (SS), assessing the sensitivity of an individual to basic physical sensations and pleasures, a tendency for sensation-seeking and risk-taking behaviour; Empathy scale (EMP) assessing sensitivity of an individual to another 
Table 1. Demographic characteristics of the sample.

\begin{tabular}{|c|c|c|c|c|c|c|c|}
\hline & All & $\begin{array}{c}\text { Control } \\
\text { group }\end{array}$ & $\begin{array}{c}\text { Comorbid } \\
\text { group }\end{array}$ & Depression only & Anxiety only & $\begin{array}{c}\text { Combined De- } \\
\text { pressed }\end{array}$ & $\begin{array}{r}\text { Combined } \\
\text { Anxious }\end{array}$ \\
\hline Total & 199 & 71 & 43 & 43 & 42 & 86 & 85 \\
\hline Males/Fem & $86 / 113$ & $28 / 43$ & $19 / 24$ & $19 / 24$ & $20 / 22$ & $38 / 48$ & $39 / 46$ \\
\hline Age: range & $18-87$ & $18-87$ & $18-82$ & $19-81$ & $19-72$ & $18-87$ & $19-81$ \\
\hline Mean & 38.76 & 41.93 & 41.87 & 43.51 & 43.53 & 41.16 & 43.52 \\
\hline SD & 14.29 & 13.78 & 11.99 & 14.49 & 15.21 & 14.51 & 14.77 \\
\hline \multicolumn{8}{|c|}{ Marital status (\%) } \\
\hline married & 59.30 & 64.79 & 48.84 & 53.49 & 66.67 & 51.16 & 57.65 \\
\hline divorced & 14.57 & 9.86 & 25.58 & 16.28 & 9.52 & 20.93 & 17.65 \\
\hline single & 26.13 & 25.35 & 25.58 & 30.23 & 23.81 & 27.91 & 24.71 \\
\hline \multicolumn{8}{|l|}{ Education \% } \\
\hline high school or less & 38.19 & 29.58 & 39.53 & 44.19 & 45.24 & 41.86 & 42.35 \\
\hline college or higher & 61.81 & 70.42 & 60.47 & 55.81 & 54.76 & 58.14 & 57.65 \\
\hline \multicolumn{8}{|l|}{ Work status \% } \\
\hline retired & 6.53 & 4.23 & 11.63 & 6.98 & 4.76 & 9.30 & 8.24 \\
\hline on disability & 10.55 & 9.86 & 6.98 & 20.93 & 4.76 & 13.95 & 5.88 \\
\hline unemployed & 22.11 & 19.72 & 18.60 & 27.91 & 23.81 & 23.26 & 21.18 \\
\hline employed & 60.80 & 66.20 & 62.79 & 44.19 & 66.67 & 53.49 & 64.71 \\
\hline
\end{tabular}

person's emotional state, and Sensitivity to Probabilities (PRO) scale assessing ability of an individual for adequate understanding and expectations of probable events, the efficient extraction and processing of new knowledge.

10-12: Emotionality group: Self-confidence scale (SLF): the tendency to be optimistic and confident (sometimes overly optimistic) in own performance, to ignore other people's warnings and criticism; Impulsivity scale (IMP): the lability of emotional reaction, a poor ability to control immediate impulses for actions; Neuroticism scale (NEU): low tolerance of uncertainty with expectations of a negative outcome.

\section{RESULTS}

ANOVA was carried out with post-hoc comparisons using the Tukey HSD method for unequal samples, for 3 separate analyses 1) between "Controls", "Depression plus Comorbid" (Depression-C), and "Anxiety-only" groups; 2) between "Controls", "Anxiety plus Comorbid" (Anxiety-C), and "Depression-only" groups; 3) between four groups: Control, Depression-only, Anxietyonly, Comorbid Depression-Anxiety. Table 2 shows the results on the scales which had significant effects.

Figures 2-4 show that the major effects involved the temperament scales of Motor Ergonicity, Motor Tempo, Intellectual Ergonicity, Sensitivity to Probabilities, Plasticity, and Impulsivity scales of STQ-77. The $F$ and $p$ values of the effects are given in the last three lines of Table 2. In the first analysis (Figure 2) the Depression-C group had significantly higher Impulsivity scores and significantly lower scores of Motor Ergonicity, Motor Tempo, Plasticity, Intellectual Ergonicity and Sensitivity to Probabilities as compared to the Control group.

The second analysis (Figure 3) showed that the group which combined both Anxiety-only and Comorbidanxiety subgroups had higher Impulsivity and lower Motor Ergonicity and Motor Tempo scores than the Control group. The differences between the Depression-only and Control groups were similar to the first analysis, showing that depressed patients had significantly lower scores on Motor Ergonicity, Motor Tempo and Plasticity and Intellectual Ergonicity scales of STQ-77.

When the comorbid group was analyzed separately from the "depressed only" and "anxious only" groups in our third analysis there were no significant differences between the anxiety and control groups, nor between the depression and comorbid groups (Figure 4). The Comorbid group reported significantly lower physical ergonicity, plasticity, physical tempo and higher impulsivity than the Control group. The Depression group again showed lower scores of physical ergonicity, physical tempo, plasticity and intellectual ergonicity than the Control group.

\section{DISCUSSION}

There are three main findings.

1) The results show that depression had an impact on the lability of behavior. This is a new finding. When analyzed according to the dynamical aspects of activity, three out of four lability-related scales of 
STQ-77 (the mobility of initiation or of changing an activity, the lability of emotional responses, i.e. impul- sivity and tempo of physical activity) showed a significant effect in the Comorbid group, Depression

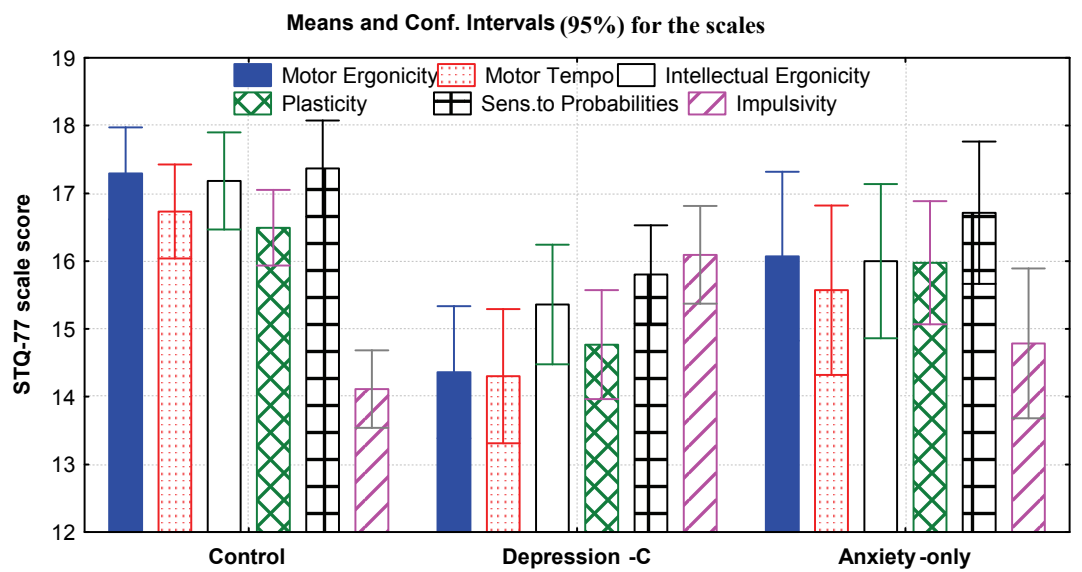

\begin{tabular}{lccc}
\hline \multicolumn{1}{c}{ Group: } & Control, $\boldsymbol{N}=\mathbf{7 1}$ & Depression- $\boldsymbol{C}, \boldsymbol{N}=\mathbf{8 6}$ & Anxiety $($ only $), \boldsymbol{N}=\mathbf{4 2}$ \\
\hline $\begin{array}{l}\text { Control } \\
\begin{array}{l}\text { Depression } \\
\text { Anxiety }\end{array}\end{array}$ & PL: 0.00, ERI: 0.00, PRO: 0.01 & ERM: 0.00, TMM: 0.00, IMP: 0.00 & \\
\hline
\end{tabular}

Figure 2. Means and conf. intervals (0.95) of the STQ-77 scores in scales with significant effects (p-level of post-hoc pairwise comparisons is indicated below each group). The "Depression" group consists of patients with and without comorbid anxiety.

Table 2. Means (M), confidence intervals (CI, 95\%), standard deviations (SD) of the STQ scores, and ANOVA effects in three analyses 1) the Depression group including the Comorbid group (F3D), 2) the Anxiety group including the Comorbid group (F3A), 3) Comorbid group was an independent group (F4). Only the scales having significant effects are shown.

\begin{tabular}{|c|c|c|c|c|c|c|}
\hline & $\begin{array}{l}\text { Motor Ergonic- } \\
\text { ity }\end{array}$ & Motor Tempo & $\begin{array}{l}\text { Intellect. Er- } \\
\text { gonicity }\end{array}$ & Plasticity & $\begin{array}{l}\text { Sensitivity to } \\
\text { Probab. }\end{array}$ & Impulsivity \\
\hline Control, $M$ & 17.30 & 16.73 & 17.18 & 16.49 & 17.37 & 14.11 \\
\hline$C I$ & $16.6-18.0$ & $16.0-17.4$ & $16.5-17.9$ & $15.9-17.1$ & $16.7-18.1$ & $13.5-14.7$ \\
\hline$S D$ & 2.86 & 2.93 & 3.03 & 2.36 & 2.99 & 2.42 \\
\hline Comorbid, $M$ & 14.33 & 14.35 & 15.60 & 14.65 & 15.63 & 16.09 \\
\hline$C I$ & $13.0-15.7$ & $12.9-15.8$ & $14.2-17.0$ & $13.4-15.9$ & $14.5-16.8$ & $15.0-17.2$ \\
\hline$S D$ & 4.32 & 4.80 & 4.52 & 4.09 & 3.81 & 3.68 \\
\hline $\begin{array}{l}\text { Depression only, } \\
M\end{array}$ & 14.40 & 14.26 & 15.12 & 14.88 & 15.98 & 16.09 \\
\hline$C I$ & $12.9-15.9$ & $12.9-15.6$ & $14.0-16.3$ & $13.8-15.9$ & $15.1-16.9$ & $15.2-17.0$ \\
\hline$S D$ & 4.81 & 4.49 & 3.70 & 3.42 & 2.94 & 3.05 \\
\hline Anxiety only, $M$ & 16.07 & 15.57 & 16.00 & 15.98 & 16.71 & 14.79 \\
\hline$C I$ & $14.8-17.3$ & $14.3-16.8$ & $14.9-17.1$ & $15.1-16.9$ & $15.7-17.8$ & $13.7-15.9$ \\
\hline$S D$ & 4.00 & 4.01 & 3.65 & 2.92 & 3.37 & 3.54 \\
\hline Depression-C, $M$ & 14.36 & 14.30 & 15.36 & 14.77 & 15.80 & 16.09 \\
\hline$C I$ & $13.4-15.3$ & $13.3-15.2$ & $14.5-16.2$ & $14.0-15.6$ & $15.1-16.5$ & $15.4-16.8$ \\
\hline$S D$ & 4.55 & 4.62 & 4.11 & 3.75 & 3.39 & 3.36 \\
\hline Anxiety-C, $M$ & 15.19 & 14.95 & 15.80 & 15.31 & 16.16 & 15.45 \\
\hline$C I$ & $14.3-16.1$ & $14.0-15.9$ & $14.9-16.7$ & $14.5-16.1$ & $15.4-16.9$ & $14.7-16.2$ \\
\hline$S D$ & 4.24 & 4.44 & 4.09 & 3.60 & 3.62 & 3.65 \\
\hline$F_{3 D}(2,196) / p$ & $11.15 / 0.00$ & $7.35 / 0.00$ & $4.86 / 0.01$ & $6.18 / 0.00$ & $4.58 / 0.01$ & $8.22 / 0.00$ \\
\hline$F_{3 A}(2,196) / p$ & $8.84 / 0.00$ & $6.28 / 0.00$ & $4.93 / 0.01$ & $4.26 / 0.02$ & $3.47 / 0.03$ & $6.21 / 0.00$ \\
\hline$F_{4}(3,195) / p$ & $7.40 / 0.00$ & $4.88 / 0.00$ & $3.36 / 0.02$ & $4.14 / 0.01$ & $3.12 / 0.03$ & $5.45 / 0.00$ \\
\hline
\end{tabular}




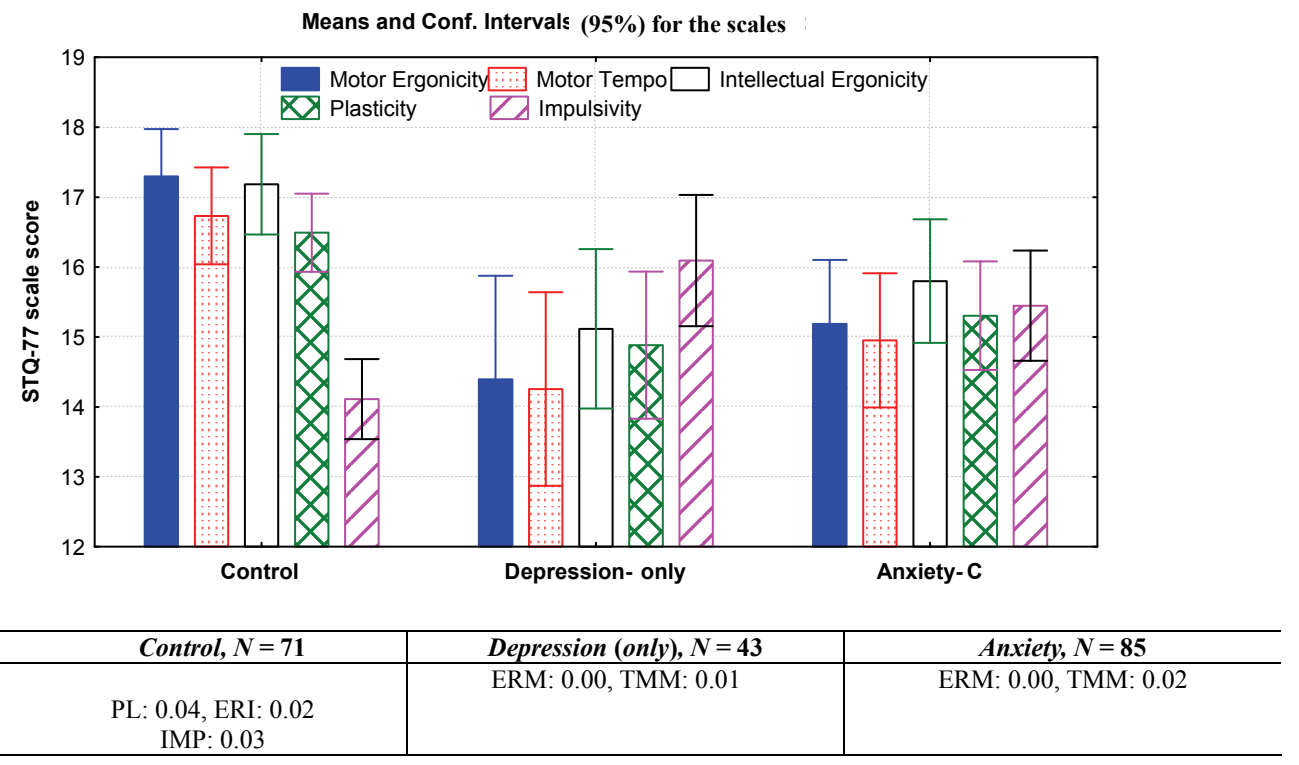

Figure 3. Means and confidence intervals (0.95) of the STQ-77 scores in scales with significant effects (p-level of pairwise comparisons is indicated below each group). The "Anxiety" group consists of patients with and without comorbid depression.

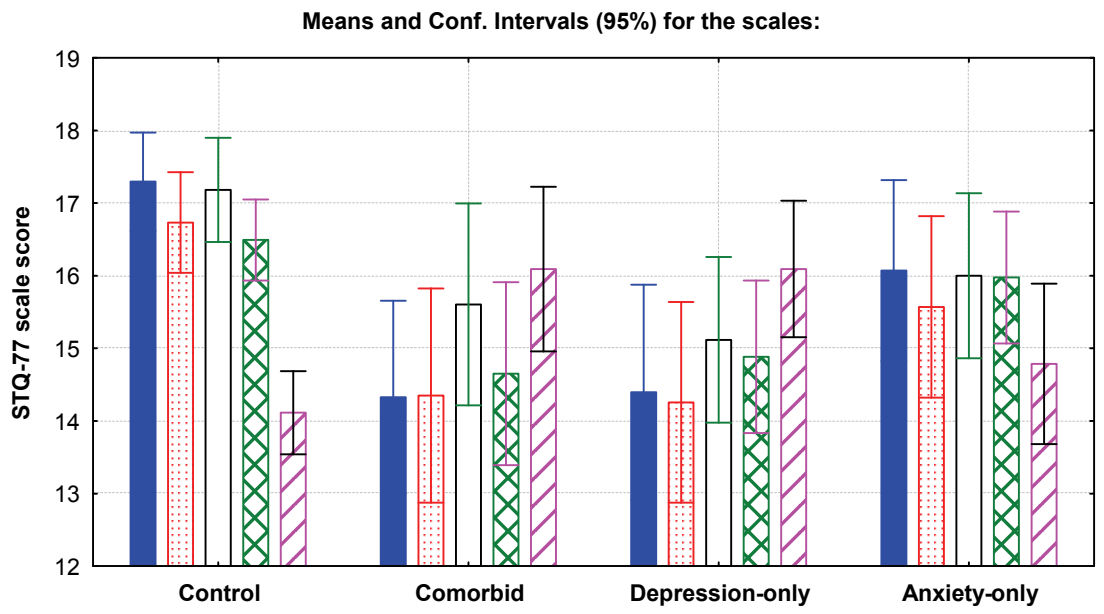

\begin{tabular}{lc|c|c|c}
\hline \multicolumn{1}{c|}{ Group: } & Control, $\boldsymbol{N}=\mathbf{7 1}$ & Comorbid, $\boldsymbol{N}=\mathbf{4 3}$ & Depression-only, $\boldsymbol{N}=\mathbf{4 3}$ & Anxiety-only, $\boldsymbol{N}=\mathbf{4 2}$ \\
\hline $\begin{array}{l}\text { Control } \\
\begin{array}{l}\text { Comorbid } \\
\text { Depression }\end{array}\end{array}$ & PL: 0.03, IMP: 0.01 & ERM: 0.00, TMM: 0.03 & ERM: 0.00, TMM: 0.02 & \\
\hline
\end{tabular}

Figure 4. Means and confidence intervals (0.95) of the STQ-77 scores in scales with significant effects in post-hoc comparison between 4 groups (p-level of pairwise comparisons is indicated below each group).

group, and especially in the Depression-C group. The speed of a response or of an action has not been the subject of previous studies of depression, as none of the temperament models, except the STQ and the Pavlovian Temperament Survey, consider the lability aspects. At the same time a "slow-down" of activity in depressed patients is noted both by the clinicians and the patients themselves. Plasticity and tempo of activity might be useful to consider as diagnostic criteria for depression.
The presence of comorbid depression and anxiety had a more significant positive impact on impulsivity than did either pure depression or anxiety.

While impulsive behavior, especially violent and self destructive behavior is not uncommon in depression, it is not a fundamental defining characteristic. Its significant expression in the comorbid group could reflect the exhaustion of the energetic capacities, which in the STQ model are related to temperament. It implies that comor- 
bidity of depression and anxiety lowers the self-regulatory capacity of an individual, as these two illnesses force an individual to live under conditions of lowered physical resources and elevated perceived situational demands. Lower scores on the Plasticity scale in depressed and comorbid patients indicate rigidity in adjusting to changing circumstances.

These results were consistent with higher rates of non-adaptive behaviour in depressed patients in comparison to non-depressed people: higher rates of suicidal attempts, shop-lifting, problems with initiation of activity perceived as apathy, problems in relationships and employment. Such behavior has components of impulsivity or rigidity in reaction to the circumstances. This was also consistent with the association between depression and scores on temperament measures from other reports. For example, Sellbom and colleagues [13] found association between depression, demoralization and the lower scores on the TCI scale of Self-directedness. The items of both the Plasticity scale of the STQ-77 and the Self-directedness scale of the TCI describe the ability of a person to generate a new action, and lower scores on these scales indicate apathy and indecisiveness, i.e. symptoms noted in depression. Combined with the higher scores on the Impulsivity scale, the results on the Plasticity scale show that comorbidity of depression and anxiety compromises the responsiveness of behavior. It causes behavior to swing between immediate, impatient reaction and rigid, inertial delay in adjustment, i.e. between the extreme high and low ends of reactivity.

2) The most significant differences on the temperament scales of the STQ-77 reflected a lowered physical capacity in depression, i.e. patients with comorbid depression and depression-only had significantly lower scores than the control group on the scales of Motor Ergonicity, Motor Tempo and Plasticity. These scales describe (respectively) the ability of an individual to sustain intense and/or prolonged physical activity, to maintain a high speed in such activity or to change the course of activity in a timely manner. The lowered capacity described by these scales may reflect the effect of psychomotor retardation and lethargy induced by the depression.

These results suggest that there may be an interaction between chemical-biological factors underlying temperament and depression. The fact that depressed patients often improve with pharmacological treatment supports ideas about the chemical-physiological basis of depression, often attributed to the specifics of neurotransmitters. On the other hand, the dependence of temperament traits upon endocrinal-humoral regulation has been noted since the time of Hippocrates and is considered to be the basis of the consistency of temperament traits. The significant correlations between depression and the Harm-avoidance scale of the TCI which were found in previous studies might be explained on the basis of the association between depression and fatigue, and not just the desire to avoid harm. The Harm avoidance scale contains items referencing "fatigability". Jiang and colleagues [10] used both TCI and the Fatigue Symptom Checklist and found that the Harm avoidance scale was positively correlated with fatigue. The current study shows a significant negative impact of depression on motor ergonicity, i.e. increased fatigability. This demonstrates the benefits of having a scale related to physical energy separately from the scales measuring emotionality and endurance in social and mental activities. It also supports the idea of activity-specific symptoms and temperament traits [22,24,25].

3) The ability to sustain attention on a mental task (as measured by the Intellectual Ergonicity scale of STQ-77) and the ability to learn new information (as measured by the Sensitivity to Probabilities scale) were significantly lower in the combined Depression group than in the Depression-only, Anxiety and Control groups. This is consistent with such symptoms of depression as "inability to focus" and informational withdrawal. This was also consistent with the findings using other temperament models. Thus, Healy and Kulig [12] used the Dimensions of Temperament Survey and measures of anxiety and attentional control and found associations between anxiety and attentional control. Hundt and colleagues [8] used Gray's 2-component model of Behavioral Activation/ Behavioral Inhibition Systems and found that high inhibition predicted poor attention and ADHD symptoms.

From the standpoint of the STQ-77, the differences between the Anxiety groups and the normal controls were less significant than the differences between the Depression groups and controls. This could reflect a more debilitating effect of depression than anxiety on normal functioning and a stronger association of depression with the same chemical-biological factors that determine temperament. The differences in scores appear to show a graded response as a function of the disorder, depression having the greatest impact followed by the cormorbid state, then anxiety and finally normality. This graded effect holds for both the positive as well as the negative effects and suggests that in their underlying effect on the neurophysiological underpinnings of temperament, depression, anxiety and normality lie along a continuum, in keeping with the current hypothesis that these disorders lie along a spectrum of psychopathology. That the comorbid group behaves more like the depressive group also suggests that depression may be the more dominant component and the cormorbid group consists more of anxious depressives rather than de- 
pressed worriers.

The main limitation of this study is associated with a use of a self-report measure, such as the STQ-77. While self-report measures are commonly used in psychiatric practice and research, one should always remember the limitations of their validity. The STQ-77 has a validity scale which allows one to screen for the high social desirability tendency and to select out invalid protocols. This improved the validity of our results but did not completely eliminate the measurement errors expected for self-report measures.

This study shows that depression has a significant impact on lability of activity (tempo, plasticity and impulse control), compromising the responsiveness of behavior through an increase in rigidity and impulsivity. Our results also show that far from simply providing an overall modulating effect, depression and anxiety appear to associate mostly with areas related to physical activity and not to intellectual or verbal activity.

\section{ACKNOWLEDGEMENTS}

The authors would like to acknowledge the hard work of Ms. Natalia Gregory in processing the data of this article.

\section{REFERENCES}

[1] Spinhoven, P., DeRooij, M., Heiser, W., Smit, J.H. and Penninx, B.W. (2009). The role of personality in comorbidity among anxiety and depressive disorders in primary care and specialty care: A cross sectional analysis. General Hospital Psychiatry, 31(5), 470-477.

[2] Moffitt, T.E., Harrington, H., Capsi, A., Kim-Cohen, J., Goldberg, D., Gregory, A.M. and Poulton, R. (2007) Depression and generalized anxiety disorder: Cumulative and sequential comorbidity in a birth cohort followed prospectively to age 32 years. Archives of General Psychiatry, 64(6), 651-660.

[3] Moller, H.J. (2002) Anxiety associated with comorbid depression. Journal of Clinical Psychiatry, 63(13), 2226.

[4] Kant, I. (1798) Anthropology from a pragmatic point of view. (M. Gregor, trans.) Martinus Nijhoff, The Hague, 1974.

[5] Smillie, L., Bhairo, Y., Gray, J., Gunasinghe, C., Elkin, A., McGuffin, P. and Farmer, A. (2009) Personality and the bipolar spectrum: Normative and classification data for the Eysenck Personality Questionnaire-R. Comprehensive Psychiatry, 50(1), 48-53.

[6] Thayer, R.E. (1989) The biopsychology of mood and arousal. Oxford, New York.

[7] Gray, J.A. (1982). The neuropsychology of anxiety: An enquiry into the functions of the septo-hippocampal system. Oxford University Press, Oxford.

[8] Hundt, N.E., Kimbrela, N.A., Mitchella, J.T. and Nelson-Graya, R.O. (2008) High BAS, but not low BIS, predicts externalizing symptoms in adults. Personality and Individual Differences, 44(3), 565-575.
[9] Farmer, R.F. and Seeley, J.R. (2009) Temperament and character predictors of depressed mood over a 4-year interval. Depression and Anxiety, 26(4), 371-381.

[10] Jiang, N., Sato, T., Hara, T., Takedomi, Y., Ozaki, I. and Yamada, S. (2003) Correlations between trait anxiety, personality and fatigue study based on the temperament and character inventory. Journal of Psychosomatic Research, 55(6), 493-500.

[11] Mehrabian, A. (1995) Distinguishing depression and trait anxiety in terms of basic dimensions of temperament. Imagination, Cognition and Personality, 15(2), 133-143.

[12] Healy, B. and Kulig, J. (2006) Temperament, Anxiety, and Attentional Control. Psychological Reports, 98(1), 23-29.

[13] Sellbom, M., Ben-Porath, Y.S. and Bagby, R.M. (2008) On the hierarchical structure of mood and anxiety disorders: Confirmatory evidence and elaboration of a model of temperament markers. Journal of Abnormal Psychology, 117(3), 576-590.

[14] Weiss, A., Sutin, A.R., Duberstein, P.R., Friedman, B., Bagby, R.M. and Costa, P.T. (2009) The personality domains and styles of the five-factor model are related to incident depression in Medicare recipients aged 65 to 100. American Journal of Geriatric Psychiatry, 17(7), 591-601.

[15] Rubino, I.A., Zanasi, M., Robone, C. and Siracusano, A. (2009) Personality differences between depressed melancholic and non-melancholic inpatients. Australian and New Zealand Journal of Psychiatry, 43(2), 145-148.

[16] Pavlov, I.P. (1941) Lectures on conditioned reflexes, II. International Publishers, New York.

[17] Kretschmer, E. (1925) Physique and Character: An investigation of the nature of constitution and of the theory of temperament. (W. Sprott, trans.) Harcourt Brace, New York.

[18] Rusalov, V.M. (1979) Biologicheskiye osnovi individual' no-psichologicheskih razlichiy (Biological basis of individual psychological differences). Nauka, Moscow, 1979.

[19] Rusalov, V.M. (1989) Object-related and communicative aspects of human temperament: A new questionnaire of the structure of temperament. Personality and Individual Differences, 10(8), 817-827.

[20] Rusalov, V.M. (1997) Questionnaire of formal-dynamical properties of individuality. Manual, Russian Academy of Sciences, IPAN Press, Moscow.

[21] Rusalov, V.M. and Trofimova, I.N. (2007) Structure of temperament and its measurement. Psychological Services Press, Toronto.

[22] Trofimova, I. (2010a) Exploration of the activity-specific model of temperament in four cultures. International Journal of Psychology and Psychological Therapy, 10(1), 79-95.

[23] Trofimova, I. (2010b) An investigation into differences between the structure of temperament and the structure of personality. American Journal of Psychology. In Press.

[24] Trofimova, I. (2009) Exploration of the benefits of an activity-specific test of temperament. Psychological Reports, 105(2), 643-658.

[25] Trofimova, I. (2010c) Questioning the "general arousal" models. Open Behavioral Sciences and Psychology Journal, 4, 1-8. 


\section{Supplementary Material: A Summary of the STQ Validation}

During the experimental validation of the STQ in the 1980-90s, the performance of subjects on the following measures were compared with STQ scales in a series of studies: speed of writing, reading and generation of words, maximal and optimal tempo of performance in sensory-motor tasks and intellectual (including unsolvable) tasks, performance on non-verbal tasks with which subjects were unfamiliar, rigidity of perception in tactile and visual modalities, duration of the switch from one way of solving the task to another, mobility in attention, variability in line drawing (Rusalov, 1979, 1989, Rusalov and Trofimova, 2007). The first version of STQ had 8 scales: the four temperament scales (ergonicity, plasticity, tempo and emotionality) assessed in social and physical activity. Each scale had 12 items (Rusalov, 1989).

The Extended version included additional 4 scales related to intellectual activity. In the studies of the concurrent validity of the initial STQ it was compared to Eysenck's EPQ (Brebner and Stough, 1993; Rusalov, 1989; Zinko, 2006), NEO-FFI (Bodunov et al., 1996, Dumenci, 1995), Strelau's PTS (Bodunov et al., 1996; Ruch et al., 1991; Strelau, 1999, Trofimova, 2009), meaning attribution to neutral objects (Trofimova, 1999), the Motivation for Achievement scale (Vorobieva, 2004), adaptivity strategies in the Dembo-Hoppe Level of Aspiration experiment (Zin'ko, 2006), 25 measures of Mobility (Rathee and Singh, 2001), Dissociative Experiences Scale (Beere and Pica, 1995, Vasyura, 2008).). References to STQ validation with the Rogers Adaptivity scale, the Torrance's Nonverbal Tests of Creative Thinking, Rotter's Locus of Control scale, a choice of profession, with other 8 measures of plasticity, STAI, MAS, Wechsler, Shepard and Gotshield Figure tests, Rosenzveig test, Cattell's 16-PF inventory, and with the school grades of high-school students, can be found in the work of Rusalov and Trofimova (2007).

The administration of the English version of the STQ (STQ-E) to American, Australian and Canadian samples demonstrated that it has a factor structure similar to that of the Russian language version, and that it has good reliability and internal consistency (Bishop et al., 1993; Bishop, Hertenstein, 2004; Dumenci, 1995, 1996 (initial version of STQ); Rusalov, 1997, 2004; Stough et al., 1991; Rusalov and Trofimova, 2007). Chinese (STQ-C), Urdu (STQ-U) and Polish (STQ-P) Extended versions of the STQ, administered among corresponding populations, showed reliability coefficients in the range $0.70-0.86$, item-total correlations in the range $0.42-0.73$, and all versions demonstrated robust factor structures similar to those of the original version (Trofimova, 2010a).

The Confirmatory Factor Analysis of the Compact STQ (STQ-77) using data from a Canadian sample shows a satisfactory fit of the traditional 4-factor STQ activity-specific model, grouping the scales to the factors of Motor, Social, Intellectual activity and Emotionality and having 2 correlated residuals (from the new scale of Sensitivity to Sensations to Impulsivity and Neuroticism scales) with the CFI $>0.90$, RMSEA $<0.07$ and RMSR $<0.06$ (Trofimova, 2010b).

The studies of reliability and content, concurrent and discriminant validity of STQ-77 scales showed that the reliability of these scales is in the range of $0.70-0.86$. The time of testing correlated statistically significantly with the Social Tempo scale $(\mathrm{r}=-0.31)$ (Trofimova and Sulis, 2009), and the time of performance on a task involving the classification of 25 common words also had the most significant negative correlations with Social Tempo, as well as with Self-Confidence scale of STQ-77 ( -0.36 and -0.29 , respectively) (Trofimova, 2010c). High school grades show activity-specific correlations with the STQ-77 scales (Trofimova and Sulis, 2009): the grades in athletics correlate with the STQ-77 scales of Motor Ergonicity and Tempo $(r=0.53$ and 0.45$)$, the grades in verbal assignments have $r=0.28$ with Social Ergonicity, and $r=0.27$ with Social Tempo scale, and the grades in math and science correlate only with the scales of Intellectual Ergonicity and Plasticity $(r=0.26$ and 0.22, respectively) (Trofimova and Sulis, 2009). Significant positive correlations are found between the new STQ-77 scales of Impulsivity, Sensitivity to Sensations, Empathy and the corresponding scales of Impulsiveness $(r=0.51)$, Venturesomeness (0.64) and Empathy (0.73) of Eysenck's I-7 questionnaire (Trofimova and Sulis, 2009). STQ-77 Sensitivity to Sensation scale shows good agreement with Impulsivity scale $(r=0.68)$ and Zuckerman Sensation Seeking Scale $(r=0.37)$ (Trofimova, 2010b).

Extraversion, as measured by the Big Five (NEO-FFI), correlates with Social Ergonicity and Impulsivity with $\mathrm{r}$ $=0.46$ and 0.52 , respectively, and Neuroticism scales of NEO-FFI and STQ-77 correlate with $\mathrm{r}=0.38$, and all these values show large effect sizes (Trofimova, 2010b). Openness to Experience of Big Five correlate most significantly with the STQ-77 scales of Intellectual Ergonicity $(r=0.31)$, Sensitivity to Probabilities $(r=0.40)$, Impulsivity $(r=0.25)$ and Empathy $(r=0.52)$; the scale of Agreeableness of Big Five correlate most significantly with the Empathy scale of the STQ-77 ( $r=0.46)$, and the scale of Conscientiousness of Big Five has the most significant correlation with the STQ-77 scales of Motor Ergonicity $(\mathrm{r}=0.35)$ and Intellectual Ergonicity $(\mathrm{r}=$ 
0.34).

\section{Additional References:}

Beere, D. and Pica, M. (1995) The predisposition to dissociate: The temperamental traits of flexibility/rigidity, daily rhythm, emotionality and interactional speed. Dissociation, 8(4), 236240.

Bishop, D., Jacks, H. and Tandy, S. (1993) Structure of temperament questionnaire (STQ): Results from a U.S. sample. Personality and Individual Differences, 14(3), 485-487.

Bishop, D. and Hertenstrein, M. (2004) A confirmatory factor analysis of Structure of Temperament Questionnaire. Educational and Psychological Measurement, 64(6), 1019-1029.

Bodunov, M.V., Bezdenezhnykh, B.N. and Alexandrov, Yu.I. (1996) Peculiarities of psychodiagnostic test item responses and the structure of individual experience. Psychological Journal (Psikhologicheskiy Zhurnal), 17(4), 87-96.

Dumenci, L. (1996) Factorial validity of scores on the structure of temperament questionnaire. Educational and Psychological Measurement, Sage Publications, US, 56(3), 487-493.

Rathee, N. and Singh, R. (2001) Mobility or/and lability of the nervous processes as temperamental trait(s). Personality and Individual Differences, 31, 1091-1104.

Ruch, W., Angleitner, A. and Strelau, J. (1991) The strelau temperament inventory-revised (STI-R): Validity studies.
European Journal of Personality, 5(4), 287-308.

Rusalov, V.M. (2004) Formal-dynamical properties of individual (Temperament). Short theory and methods of measurement for various age groups. Russian Academy of sciences, Moscow, IPAN (In Russian).

Stough, C., Brebner, J. and Cooper, C. (1991) The Rusalov structure of temperament questionnaire (STQ): Results from an Australian sample. Personality and Individual Differences, 12(12), 1355-1357.

Trofimova, I. (1999) How people of different age, sex and temperament estimate the world. Psychological Reports, 85(2), 533-552.

Trofimova, I. and Sulis, W. (2009) Is temperament activity-specific? Validation of the structure of temperament questionnaire - Compact (STQ-77). Submitted to Journal of Personality Assessment.

Vasyura, S.A. (2008) Psychology of male and female communicative activity. Spanish Journal of Psychology, 11(1), 289300.

Vorobieva, E.V. (2004) Modern psychogenetic studies of intelligence and theory of motivation for achievements. Journal of Applied Psychology, 3, 53-59.

Zin'ko, E.V. (2006) Characteristics of self-image and of level of aspiration and its parameters. Psychological Journal (Psikhologicheskii Zjurnal), 3, 18-30; 4, 15-25. 